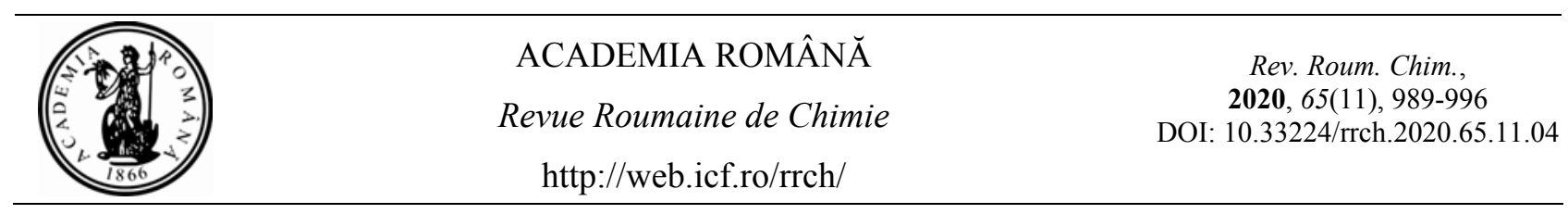

\title{
UV-VIS STUDIES ON INTERACTION BETWEEN SODIUM DIOCTYLSULFOSUCCINATE (AOT) AND METHYL RED
}

\author{
Binita KHADKA and Ajaya BHATTARAI* \\ Department of Chemistry, M.M.A.M.C., Tribhuvan University, Biratnagar, Nepal
}

Received April 6, 2020

\begin{abstract}
This paper deals with the interaction of sodium dioctylsulfosuccinate (AOT) and methyl red (MR) by UV-Vis spectrophotometry at $298.15 \mathrm{~K}$. The concentration of AOT varies from 0 to $0.12530 \mathrm{~mol} / \mathrm{kg}$ and the concentration of methyl red is $3.71 \times 10^{-5} \mathrm{M}$. Here, water concentration is defined by the R parameter. The R parameter in this study varied from 0 to 20 .

Two intense absorption bands were observed within the 380 to $540 \mathrm{~nm}$ wavelength of methyl red in methanol. Band 1(380 to $450 \mathrm{~nm})$ of methyl red contains a higher absorbance peak than band 2 ( 450 to $540 \mathrm{~nm}$ ). When the concentration of AOT increased, band 1 $(380-450 \mathrm{~nm})$ of methyl red decreased the absorbance peak, whereas band 2 (450 to $540 \mathrm{~nm}$ ) of methyl red increased the absorbance peak with increasing AOT concentration. Band 1 shows a hypochromic shift of methyl red with an increase in AOT concentration, whereas band 2 shows a hyperchromic shift of methyl red with an increase in AOT concentration. On comparing the absorbance versus concentration graph for different $\mathrm{R}$ parameters, we observed that absorbance increases with the increase in the $\mathrm{R}$ parameter. The binding constant and distribution constant were calculated using a nonlinear regression procedure (NLREG). The experiment shows the effect of methanol, AOT and water concentration on methyl red.
\end{abstract}

\section{INTRODUCTION}

Surfactants that are displayed at low concentrations in a framework adsorb on the surfaces and uniquely change the interfacial free energies of those surfaces and interfacing. Such conduct may be a result of the characteristic structure of surfactant molecules, which consist of two parts. One may be a so-called hydrophobic and the other is hydrophilic. The hydrophobic group is, as a rule, a long-chain hydrocarbon; the hydrophilic group is exceedingly polar or ionic. For the most part, surfactants are classified depending on the nature of the hydrophilic group as anionic, cationic, zwitterionic and nonionic. $^{1}$

However, the property of being adsorbed at surfaces or interfacing surfactant molecules depending on solvent polarity can form colloidal measured clusters called micelles. Among numerous, micellization is an imperative interfacial marvel since micelles have ended up a subject of interest to the natural chemists for illustration as nano catalytic reactors and by to the organic chemists because of micelles likeness to space structures found in natural films. $^{2}$

AOT (sodium dioctylsulfosuccinate) is an anionic surfactant (Fig. 1) that has been widely used nowadays. It has large functional uses at present and will be more in the coming moment. It has been used as a wetting and emulsifying agent in industrial, pharmaceutical, cosmetic and food applications. It is a surfactant that can form reversed micelles in nonpolar solvents. The capacity of AOT molecules for aggregate outcomes from the joint activity of spatially separated hydrophilic and hydrophobic moieties of AOT. Such micelles are constructed as inner cores involved by the hydrophilic head groups covered by the hydrocarbon tails, which are amplified into the bulk of non-polar solvents. ${ }^{1}$ 


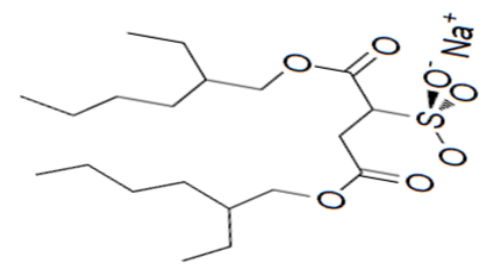

Fig. 1 - Structure of an AOT Molecule.

It has been indicated that the curious limit of AOT reversed micelles for a lot of water relies upon the encompassing non-polar solvent and temperature. ${ }^{3}$ Depending upon the measure of water purported water pool development into a center of reversed micelles is conceivable. The measure of water in such a framework is given by the parameter $\mathrm{R}$, characterized as water to AOT fixation proportion: $\mathrm{R}=\left[\mathrm{H}_{2} \mathrm{O}\right] /[\mathrm{AOT}]{ }^{4}{ }^{4}$

Methyl red (2-(N, N-Dimethyl-4-amino phenyl) azobenzene carboxylic acid), also known as C.I. Acid Red 2, is an indicator dye that changes red in acidic solutions at a $\mathrm{pH}$ of 5.5.,6 The acid form of methyl red exists in zwitterionic as HMR, whereas in its basic form, it is in anionic form as $\mathrm{MR}^{-7,8}$ as shown in (Fig. 2) and it is a dark red crystalline powder. In microbiology, it is utilized in the methyl red test, utilized to detect bacteria producing stable acids by the mechanism of mixed acid fermentation of glucose. ${ }^{9}$

Nowadays, the interaction between dyes and surfactants is an interesting subject. ${ }^{10-12}$ It has been reported that if a surfactant is added to a dye solution at sub-micellar concentrations, the surfactant monomers and dye may interact with each of the reactions. The formation of ion association complexes between ionic surfactants and dyes with the opposite charge at surfactant concentrations below the critical micelle concentration (CMC), is aided by the literature. ${ }^{13-16}$

Various techniques such as membrane-selective electrodes, ${ }^{17}$ polarography, ${ }^{18}$ and potentiometry ${ }^{10,19}$ have been applied for dye and surfactant interactions.

There have been some spectrophotometric measurements of dyes in the presence of surfactants $^{12,20-27}$ and particularly, even some studies of methyl red with AOT were noticed in the literature..$^{28-31}$ Our aim was to see the spectrophotometric measurements of methyl red in AOT/methanol and AOT/methanol/water systems. However, there is no literature on the UV-Vis study of methyl red in AOT/methanol and with increasing amounts of water in methanol.

In this paper, the results are reported from the UV-Visible spectrophotometer of methyl red in the presence of AOT by increasing the amount of water in methanol. The amount of water in $\mathrm{AOT} / \mathrm{methanol} /$ water systems, regardless of whether they have a surfactant concentration below the critical micellar concentration CMC (no reverse micelles are formed) or above $\mathrm{CMC}$ (reverse micelles are formed). The CMC of AOT in methanol was estimated at $\sim 8.7 \mathrm{mM}^{32}$

We have tried to explain the effect of varying concentrations of surfactant (AOT) on methanol, in systems with and without water, by using the methyl red absorption spectra.

Here, the distribution constant and binding constant are also calculated and described its role in solubility.

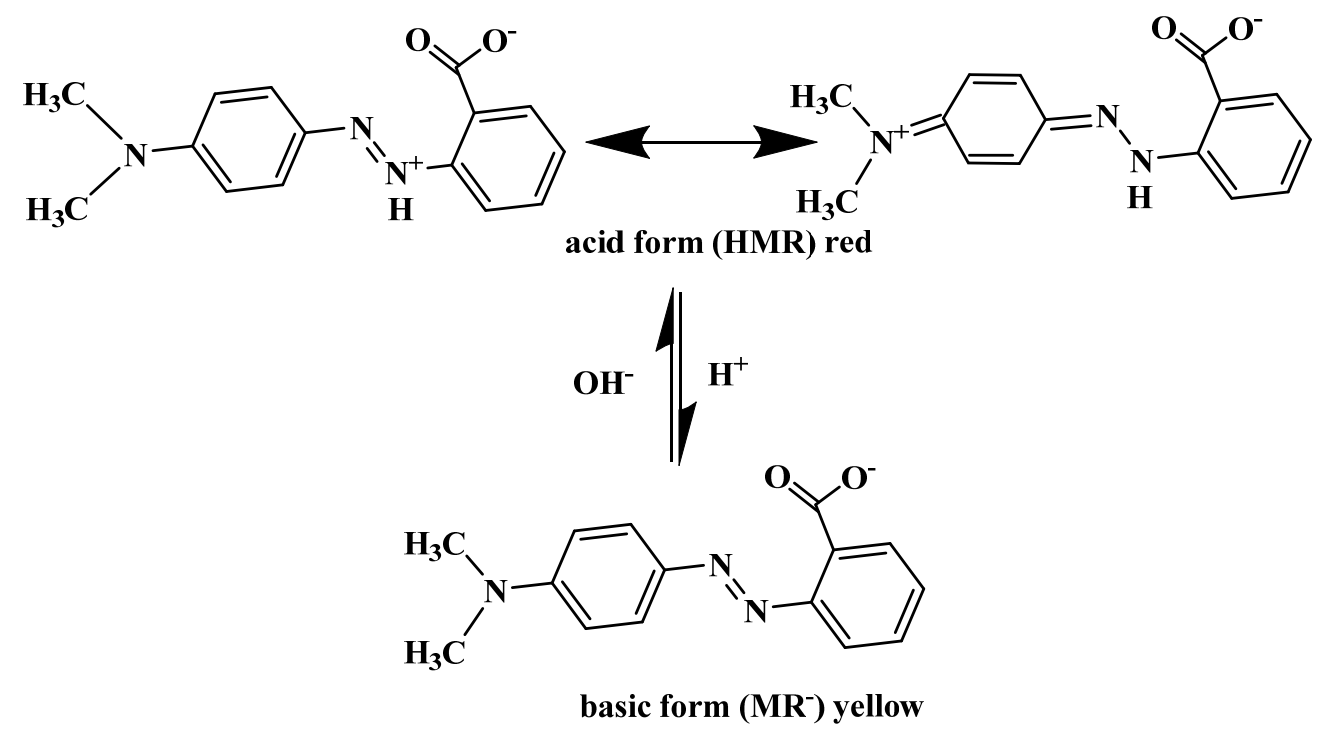

Fig. 2 - Acid and base forms of methyl red. 


\section{RESULTS AND DISCUSSION}

\section{Interaction between surfactant and dye by absorption spectroscopy}

Absorption spectroscopy corresponds to fluorescence spectroscopy, in which fluorescence manages changes from the energized state to the ground state, while absorption measures transitions from the ground state to the excited state. ${ }^{33}$

The size of the micelles strongly depends on the water content defined by the $\mathrm{R}$ parameter as the ratio of $\mathrm{H}_{2} \mathrm{O}$ to AOT concentrations.

Here, the absorption spectra of methyl red show two intense bands between 380 and $540 \mathrm{~nm}$, as presented in Figure 3. Band $1(380-450 \mathrm{~nm})$ of methyl red contains a higher absorbance peak than band 2 (450 to $540 \mathrm{~nm}$ ) in methanol.

The concentration of AOT used in this experiment varied from 0 to $0.1253 \mathrm{~mol} / \mathrm{kg}$. In our experiments, AOT concentrations were full range and $\mathrm{R}$ parameter values were 0,10 and 20 . As we tried to do further for 30 and 40, but due to the cloudy nature of the solution, we were unable to do further experiments after $\mathrm{R}=20$.

Here, we present Figure 4 of the dependence of absorbance on the wavelength of methyl red in methanol at different concentrations of AOT with $\mathrm{R}=0$.

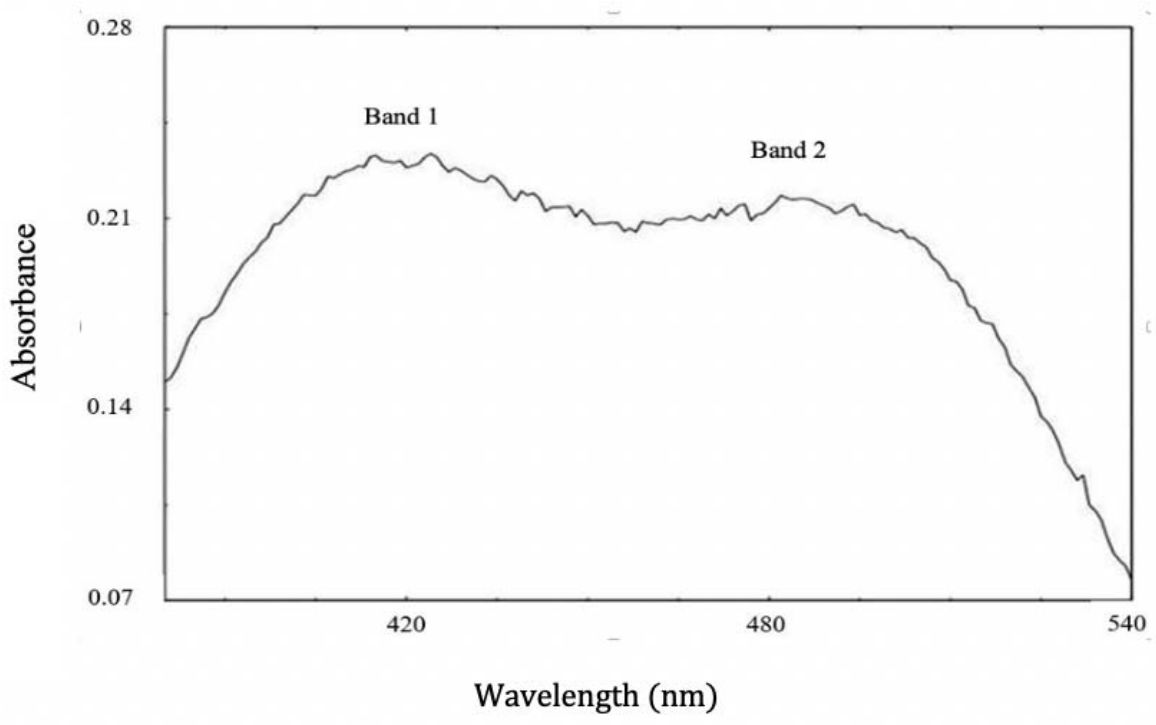

Fig. 3 - Absorption spectra for methyl red in methanol.

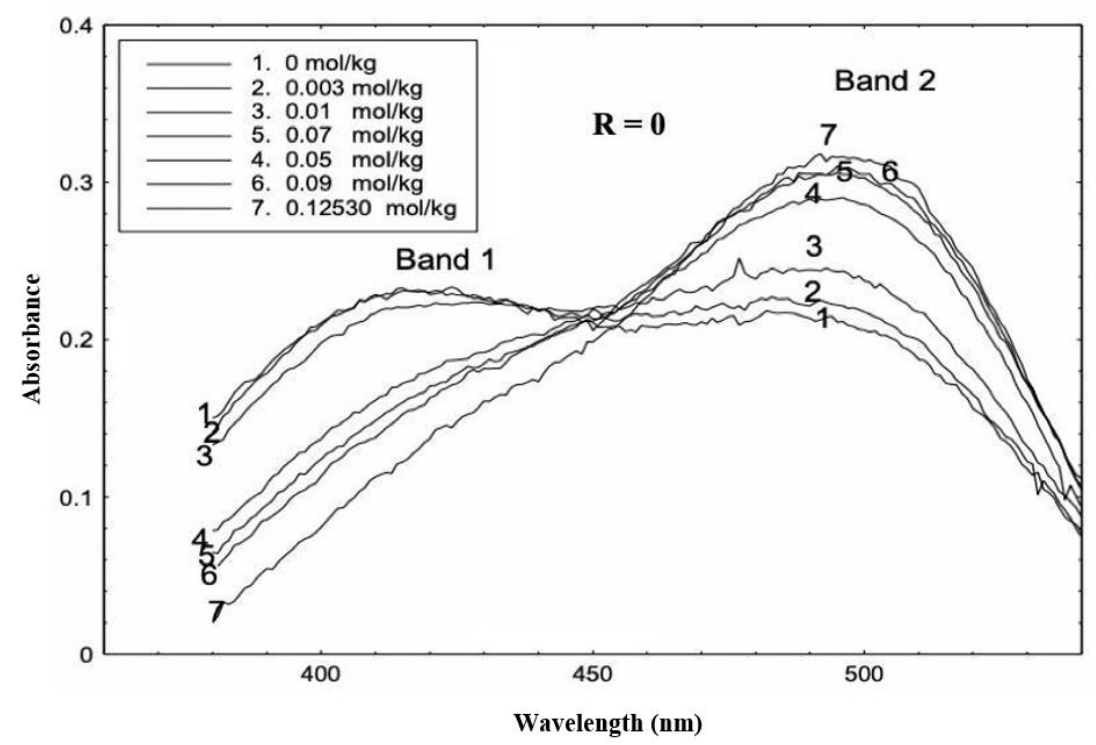

Fig. 4 - Absorption spectra for methyl red with wavelength in methanol at different concentrations of AOT solution in methanol $(\mathrm{R}=0)$. 


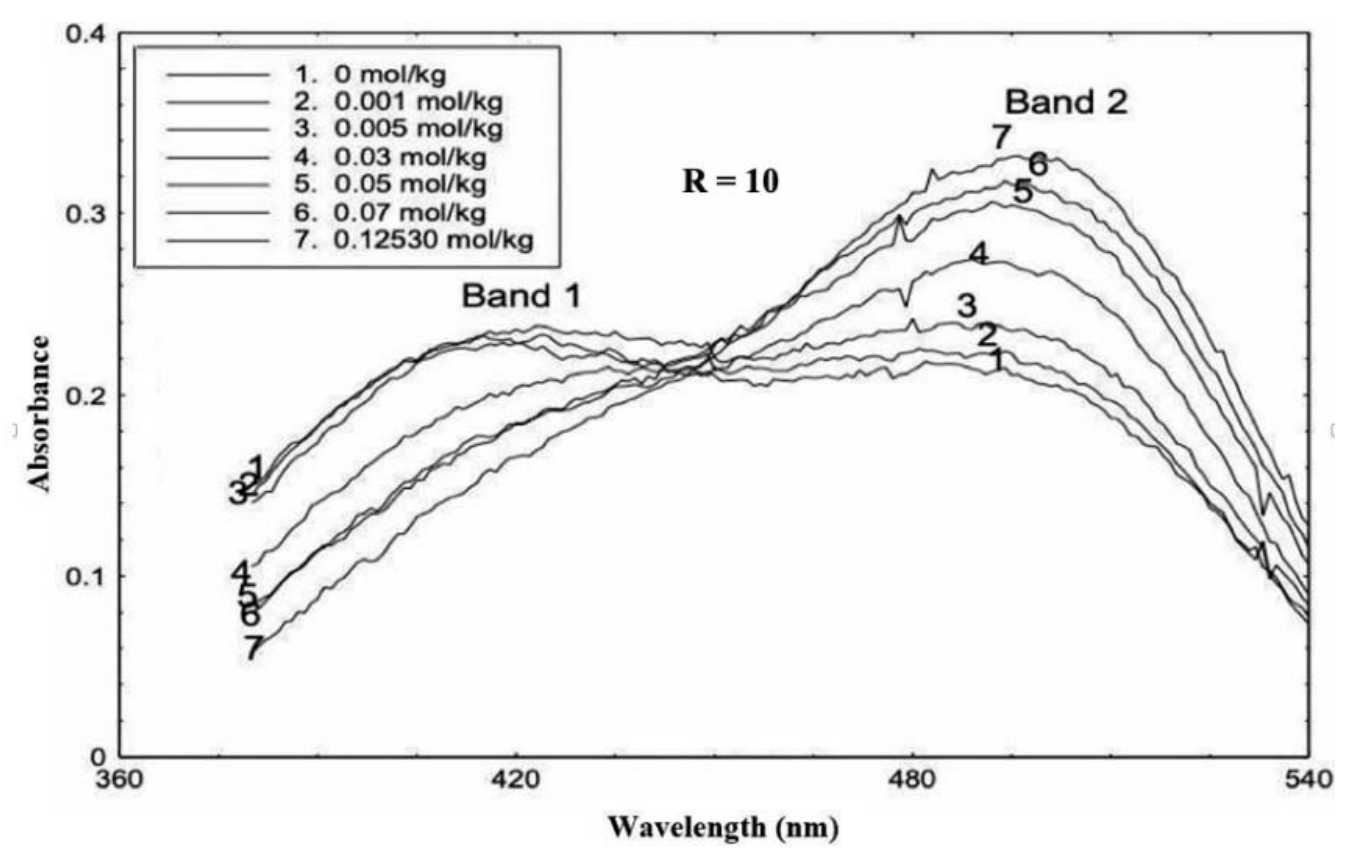

Fig. 5 - Absorption spectra for methyl red with the wavelength in methanol at different concentrations of AOT solution in methanol $(\mathrm{R}=10)$.

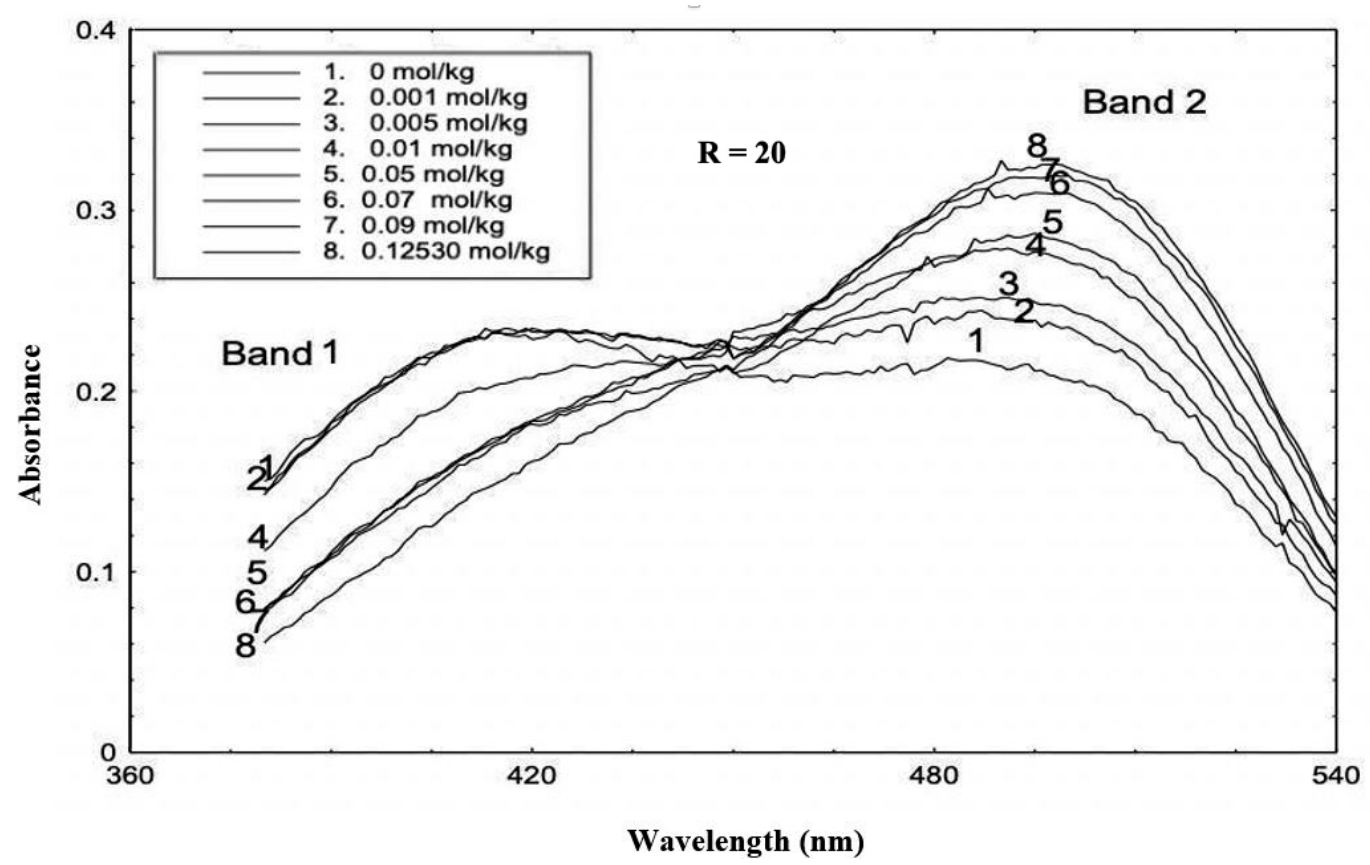

Fig. 6 - Absorption spectra for methyl red with the wavelength in methanol at different concentrations of AOT solution in methanol $(\mathrm{R}=20)$.

We can explain the hypochromic/hyperchromic shifts due to the azo-hydrazone transition of MR in AOT/methanol $(\mathrm{R}=0)$.

In Figure 4, we can see two absorption bands. For absorption band 1, the absorbance maximum of MR at a wavelength of $413 \mathrm{~nm}$ for the lower concentration of AOT and with the rise in the concentration of AOT, the absorbance of MR diminishes, showing a hypochromic shift in the intensity of absorbance, which is the same as the absorbance spectra of the azo form of MR. Such type of interaction of MR with SDS and CPS was investigated by Jirasová et al. in 1990. ${ }^{34}$

For absorption band 2, the maximum absorbance of MR was observed at the highest concentration of AOT. The maximum peak was observed at $503 \mathrm{~nm}$, which we called $\lambda_{\max }$, which is the same as the absorbance spectra of the 
hydrazone form of MR. Such a type of the absorbance peak of MR in ethanol-water-AOT is noticed in the literature. ${ }^{28}$ For band 2, the absorbance of MR increases with the increase in the concentration of AOT showing a hyperchromic shift in the intensity of absorbance.

In Fig. 5 for $\mathrm{R}=10$, a similar pattern was observed as in $\mathrm{R}=0$. We observed from band 2 that the absorption intensity is higher for increasing the value of the $\mathrm{R}$ parameter i.e. absorption intensity is higher for $\mathrm{R}=10$ than for $\mathrm{R}=0$.

A similar pattern was observed for $\mathrm{R}=20$ as $\mathrm{R}=0$ and 10 . In addition, the absorption intensity for $\mathrm{R}=20$ is higher than that for 0 and 10 , respectively, for the increase in AOT concentration with an increase in the $\mathrm{R}$ parameter in band 2 is observed.

Figs. 4-6 show that the absorbance intensity of the MR at $\mathrm{R}=0$ to 20 affected with increasing AOT concentration for band 2. More MR molecules can be taken into micelles as monomeric molecules with the increment of AOT concentration and absorbance rises by the hyperchromic shift. ${ }^{35}$ Such types of spectra are also observed in the literature. ${ }^{12}$

In the case of band 1 in Figs. 4-6 show, the absorbance intensity of the MR in $\mathrm{R}=0$ to 20 decreases with increasing AOT concentration. In a system consisting of MR and micelles formed with AOT are possible electrostatic interactions. These types of intermolecular interactions are also responsible for decreasing the absorbance of MR with increasing AOT concentration, and the absorbance intensity sharply decreases with the hypochromic shift. ${ }^{35}$ Such types of spectra are also observed in the literature. ${ }^{12}$

Similarly, the same pattern of the hypochromic/ hyperchromic shifts due to the azo-hydrazone transition of MR, in AOT/methanol/ water systems $(\mathrm{R}=10,20)$ was noticed as the AOT/methanol system because there was only an increase in absorbance when the amount of water increased.

It is known that MR is treated to an AOT solution having micelles distributed between the bulk organic solvent and micellar phases. By considering the good behavior of the dye in both phases, the distribution constant of the dye following the Nernstian distribution law can be given as

$$
K=\frac{m_{\mathrm{m}}}{m_{\mathrm{O}}}
$$

where $K$ is the distribution constant, $m_{\mathrm{m}}$ and $m_{\mathrm{o}}=$ the concentration of dye in the micellar and organic phases.

Following Magid and co-workers, ${ }^{36}$ the ratio of dye absorbance's band intensities $(A)$ was expressed as:

$$
A=x_{\mathrm{m}} A_{\mathrm{m}}+\left(1-x_{\mathrm{m}}\right) A_{0}
$$

Here $x_{\mathrm{m}}=$ dye mole fraction

$A_{\mathrm{m}}=$ value of corresponding to the situation when the dye completely dissolves in micellar phases, related to organic phases. In our case, the dye dissolved in methanol, so the distribution constant can be presented as

$$
K=\frac{n_{\mathrm{m}}}{n_{\mathrm{o}}[A O T] M_{A O T}}
$$

where $n_{\mathrm{m}}$ is the moles of dye in the micellar phase, whereas $n_{\mathrm{o}}$ is with organic phase, [AOT] is the molarity of AOT, and the $M_{A O T}$ is molecular weight of AOT. On analysis of the UV-VIS spectra, the binding constant $K^{\prime}$ of MR to AOT micelle is given as: ${ }^{36}$

$$
K^{\prime}=\frac{n_{\mathrm{m}}}{n_{\mathrm{o}}[A O T]}
$$

There is an association between $K$ and $K^{\prime}$ as $K^{\prime}=K^{*} M_{A O T}$

From the Poisson distribution, ${ }^{36}$ Eq. (4) can be written as

$$
x_{\mathrm{m}}=\frac{K^{\prime}[A O T]}{1+K^{\prime}[A O T]}
$$

Combination of Eq. (2) and (5), we get

$$
A=A_{\mathrm{O}}+\frac{\left(A_{\mathrm{m}}-A_{\mathrm{O}}\right) K^{\prime}[A O T]}{1+K^{\prime}[A O T]}
$$

where $A_{\mathrm{m}}$ and $K^{\prime}=$ fitted parameters, $A_{\mathrm{o}}$ values were found in a separate experiment.

Figure 7 shows the graph of AOT concentration versus absorbance for different $\mathrm{R}$ parameters of band 2. In Figure 7, we can see the graph of absorbance at different concentrations of AOT for different $\mathrm{R}=0$ to 20 . We observe that the graph is in increasing order for increasing the value of the $\mathrm{R}$ parameter respectively. The absorbance increases with an increase in the $\mathrm{R}$ parameter. 


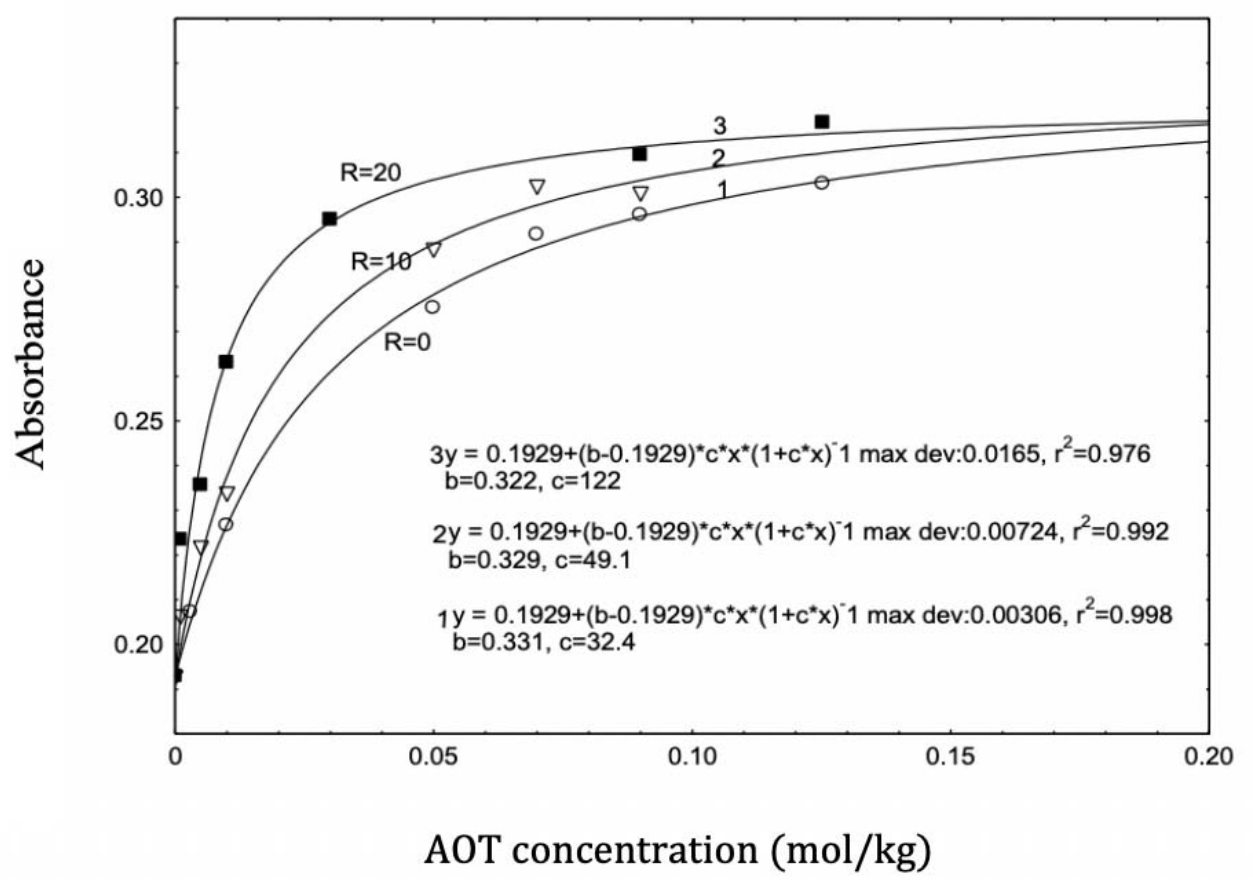

Fig. 7 - Variation of Absorbance versus AOT concentration.

Table 1

( $A_{\mathrm{m}}$ and $K^{\prime}$ ) obtained in the NLREG process of the UV-Vis data for AOT partitioning between methanol and AOT micelles measured at $298.15 \mathrm{~K}$ of different $\mathrm{R}\left(\mathrm{R}=\left[\mathrm{H}_{2} \mathrm{O}\right] /[\mathrm{AOT}]\right.$ values, and $K$ obtained from the equation: $K^{\prime}=K^{*} M A O T$

\begin{tabular}{c|c|c|c}
\hline $\mathrm{R}$ & $A_{\mathrm{m}}^{\mathrm{a}}$ & $K^{\prime}\left(\begin{array}{c}\text { (binding constant) } \\
{[\mathrm{kg} / \mathrm{mol}]}\end{array}\right.$ & $K$ (distribution constant) \\
\hline 0 & 0.331 & 32.4 & 0.0728 \\
10 & 0.329 & 49.1 & 0.1104 \\
20 & 0.322 & 122 & 0.2744 \\
\hline
\end{tabular}

${ }^{a}$ Absorbance of methyl red dissolved in the micellar phase

The equations and numerical values of these parameters are given in Figure 7. Here, the fitting parameters $\left(A_{\mathrm{m}}\right.$ and $\left.K^{\prime}\right)$ come from (b and c), respectively. It is quite interesting in Figure 7, the correlation coefficient, $\mathrm{r}^{2}=0.998$ for $\mathrm{R}=0, \mathrm{r}^{2}=0.992$ for $\mathrm{R}=10$ and $\mathrm{r}^{2}=0.976$ for $\mathrm{R}=20$. This means that as the amount of water decreased in methanol, the best fitting of the curve of absorbance versus concentration was observed or as the amount of water increased in methanol, less fitting of the curve of absorbance versus concentration was noticed. This may be due to the dielectric constant increment of the solvent system and the reduction of solubility. ${ }^{28}$

In equation (6) binding constant and solute absorption dissolved in the micellar phase were the fitting parameters in the NLREG procedure, in which experimental UV-Vis solute absorbance data were analyzed as a function of the AOT concentrations. The fitting parameters $\left(A_{\mathrm{m}}\right.$ and $K^{\prime}$ ) as well as $K$ are shown in Table 1.

From Table 1, we observe that the binding constant and distribution constant increase with increasing value of the $\mathrm{R}$ parameter. The increasing value of the distribution constant with increasing $\mathrm{R}$ parameter indicates that stronger interactions between $\mathrm{MR}$ and AOT micelles appeared in $\mathrm{R}=20$ in comparison among MR with AOT micelles appeared in $\mathrm{R}=10$ and $\mathrm{R}=0$.

\section{EXPERIMENTAL}

Sodium dioctylsulfosuccinate (AOT 98\%) was purchased from Loba Chemie Pvt. Ltd., Mumbai-400005, India. Methyl red was purchased from Ranbaxy Company, India and was used without purification. Methanol was purchased from E. Merck (India) Private Limited which was $98 \%$ pure. Water was double-distilled quality. 
MR was weighed and poured into a volumetric flask containing $50 \mathrm{ml}$ of methanol. After the mouth of the conical flask was covered and allowed to stir on a magnetic stirrer for the whole night $(24 \mathrm{~h})$. In the same way, AOT was weighed and poured into a volumetric flask containing $100 \mathrm{ml}$ of methanol and stirred on a magnetic stirrer for the whole night.

$\mathrm{R}$ parameter values were obtained between 0 and 20 by adding water to the AOT solution and was calculated as $\mathrm{H}_{2} \mathrm{O}$ to the AOT molarities ratio denoted as $\mathrm{R}$ parameter. The methyl red absorbance was recorded between $380 \mathrm{~nm}$ and $540 \mathrm{~nm}$ wavelength at $298.15 \mathrm{~K}$ using a LABTRONICS UVVis spectrophotometer (Model LT-290) single beam equipped with $10 \mathrm{~mm}$ length quartz cuvette. Such types of methyl red absorption spectra in the range of $\lambda 380-540 \mathrm{~nm}$ were also recorded in the literature. ${ }^{37}$

For each experiment, the baseline was registered for a given AOT/methanol or AOT/Methanol/ $\mathrm{H}_{2} \mathrm{O}$ and afterward a fixed volume of methyl red solution in the same solvent was added. After adding the methyl red solution, the entire liquid volume was stirred very carefully for $2 \mathrm{~min}$. During this time, methyl red molecules interacted with AOT micelles and finally distributed between the organic bulk solvent and micelles. The absorbance of methyl red was obtained as a function of the AOT concentration.

\section{CONCLUSIONS}

This study shows that the UV-Vis measurement of methyl red in AOT/methanol and AOT/ methanol/water systems at $298.15 \mathrm{~K}$ was presented as a function of AOT concentration and wavelength. Two intense absorption bands were observed within the 380-540 $\mathrm{nm}$ wavelength of methyl red in AOT/methanol and AOT/methanol/ water systems. Band 1 shows a hypochromic shift of methyl red with an increase in AOT concentration, whereas band 2 shows a hyperchromic shift of methyl red with an increase in AOT concentration. The azo-hydrazone tautomerism form of MR was observed by the change of band 1 to band 2 .

Hence, it is found that there is a solvent effect on methyl red absorbance in AOT/methanol and AOT/methanol/water systems. The graph of absorbance versus concentration for different $R$ parameters shows that the absorbance increases with the increase in water concentration in the system. It can be concluded from the above results and discussion that the increasing value of the distribution and binding constant is directly proportional to the $\mathrm{R}$ parameter, suggesting a strong interaction between methyl red and AOT micelles for $\mathrm{R}=20$ in comparison to $\mathrm{R}=10$ and $\mathrm{R}=0$.

Acknowledgments. The authors are thankful to the World Academy of Sciences (TWAS), Italy for providing research grants and also thanks go to Friends of Mahendra Morang
Adarsh Multiple Campus for purchasing the LABTRONICS UV-Vis spectrophotometer (Model LT-290) to carry out this research work.

\section{REFERENCES}

1. A. Bhattarai and H. Wilczura-Wachnik, Int. J. Pharma., 2014, 46, 14-21.

2. M. J. Rosen, "Surfactants and Interfacial Phenomena", 3th edition, John Willey \& Sons, Inc., Hoboken, New Jersey, 2004, p. 1-3.

3. F. M. Menger and G. Soito, J. Am. Chem. Soc., 1978, 100, 4376-4379.

4. J. H. Fendler, Chem. Rev., 1987, 87, 877-899.

5. J. Mendham, R. C. Denney and J. D. Barness, "Quantitative Chemical Analysis", 6th edition, W. H. Freeman, New Delhi, 2004.

6. S. Lee, J. H. Wong and S. J. Liu, Appl. Spectrosc., 2011, 65, 996-1003.

7. J. H. Zhang, Q. Liu, Y. M. Chen, Z. Q. Liu and C. W. Xu, Acta Phys.Chim. Sin., 2012, 28, 1030-1036.

8. M. R. Plutino, E. Guido, C. Colleoni and G. Rosace, Sensors and Actuators B., 2017, 238, 281-291.

9. S. K. Alexander and D. Strete, "Microbiology, A photographic Atlas for the Laboratory", Benjamin Cummings, 2000.

10. B. Simoncic and M. Kert, Dyes Pigments., 2006, 71, 43-53.

11. O. Yazdani, M. Irandoust, J. B. Ghasemi and S. Hooshmand, Dyes Pigments., 2012, 92, 1031-1041.

12. S. Tunc, O. Duman and B. Kanci, Dyes pigments., 2012, 94, 233-238.

13. M. Rashidi-Alavijel, S. Javaherian, H. Gharibi, M. Moradi, A. R. Tehrani-Bagha, A. A. Asadzadeh Sahir, Physicochem. Eng. Aspects., 2011, 380, 119-127.

14. B. Gohain, S. Sarma and R. K. Dutta, J. Mol. Liq., 2008, 142, 130-135.

15. K. Prochaska, M. Bielska and A. Sobczynska, Dyes Pigments., 2009, 80, 201-205.

16. S. M. Ghoreishi and M. S. Nooshabadi, Dyes Pigments., 2005, 65, 117-123.

17. A. Navarro and F. Sanz, J. Colloid Interface Sci., 2001, 237, 1-5.

18. B. Simoncic and M. Kert, Dyes Pigments., 2002, 54, 221-237.

19. M. Irfan, M. Usman, A. Mansha, N. Rasool, M. Ibrahim, U. A. Rana, M. Siddiq, M. Zia-Ul-Haq, H. Z. E. Jaafar and S. Ud-Din Khan, The Scientific World J., 2014, 540975.

20. J. Oakes, P. Gratton and S. Dixon, Coloration Tech., 2003, 119, 301-306.

21. J. Yang, J. Colloid Interface Sci., 2004, 274, 237-243.

22. A. R. Tehrani Bagha, H. Bahrami, B. Movassagh, M. Arami and F. M. Menger, Dyes Pigments., 2007, 72, 331-338.

23. A. Safavi, H. Abdollahi, N. Maleki and S. Zeinali, J. Colloid Interface Sci., 2008, 322, 274-280.

24. S. M. Ghoreishi, M. Behpour and A. G. Farsani, Dyes Pigments., 2007, 74, 585-589.

25. H. Akbaş and Ç. Kartal, Spectrochim. Acta Part A: Mol. Biomol. Spectroscopy, 2005, 61, 961-966.

26. H. Dezhampanah and R. Firouzi, Int. J. Research in Phys. Chem., 2012, 2, 45-48.

27. D. A. Skoog, F. J. Holler and S. R. Crouch, "Principles of Instrumental Analysis", $6^{\text {th }}$ edition, 2007. 
28. S. Sharifi, M. F. Nazar, F. Rakhshanizadeh, S. A. Sangsefedi and A. Azarpour, Optical and Quantum Electronics, 2020, $52,1-18$.

29. C. Hahn and A. Wokaun, Langmuir, 1997, 13, 391-397.

30. S. Chanda and K. Ismail, Indian J. Chem., Section A: Inorg., Bio-inorg., Phys., Theoretical \& Anal. Chem. 2009, 48A, 775-780.

31. A. T. Terpko, R. J. Serafin and M. L. Bucholtz, J. Colloid \& Interface Sci. 1981, 84, 202-205.

32. A. I. Mitsionis and T. C. Vaimakis, Chem. Phys. Letters, 2012, 547, 110-113.
33. N. Zaghbani, M. Dhahbi and A. Hafiane, Spectrochim. Acta A 2011, 79, 1528- 1531.

34. J. Jirasová, J. Bílý and L. Čermáková, Collection of Czechoslovak Chem. Comm., 1990, 55, 1491-1499.

35. A. Bhattarai and H.Wilczura-Wachnik, J. Surface Sci. Technol., 2016, 32, 17-21.

36. L. J. Magid, K. Kon-no and C. A. Martin, J. Phys. Chem., 1981, 85, 1434-1439.

37. A. C. Benchea, D. Babusca, Č. Podlipnik, D. G. Dimitriu, Anal. Lett., 2017, 50, 2711-2724. 